\title{
Role of ventricular premature beats in initiation and termination of atrial arrhythmias
}

\author{
George Csapó \\ From the Fourth Clinic of Medicine, Semmelweis University of Medicine, \\ Budapest; and the Surgical Department of the Hungarian Institute \\ of Cardiology, Budapest, Hungary
}

Clinical observations in 5 patients are presented of 42 episodes of atrial arrhythmias after ventricular premature beats which had occurred $0.04-0 \cdot 10$ sec. after the onset of the $P$ wave. In experiments in dogs, catheter electrodes were introduced into the right atrium and right ventricle through the jugular vein under chloralose $(0.10 \mathrm{~g} .1 \mathrm{~kg}$.) anaesthesia, and 5,000 pacemaker impulses were analysed. With impulses exceeding three times the diastolic impulse threshold, no arrhythmias were observed either in the case of atrial or ventricular stimulation-apart from the pacemaker pararrhythmia. During acetylcholine infusion (0.8-I.0 mg./min.), atrial stimulation elicited atrial arrhythmias in 32.6 per cent of the cases where the impulses occurred in the period of atrial vulnerability. In cases of ventricular stimulation the pacemaker-induced ventricular premature beats occurring $0.04-0.1 \mathrm{sec}$. after the onset of the $P$ wave were followed by atrial arrhythmias in 16.9 per cent of cases. It is suggested that ventricular premature beats occurring in the area of the $P$ wave, which are vulnerable for the atrium, should be termed the ' $R$ on $P$ phenomenon'. In 7 instances in 2 patients it was noted that supraventricular arrhythmias stopped immediately after the premature ventricular beats.

There are two main ways of inducing ectopic tachycardias, atrial and ventricular flutter, or fibrillation by electrical impulse. The first involves stimulation of the myocardium with high frequency, the second, stimulation in the vulnerable period of the heart cycle (Ferris, King, and Spence, 1936; Wiggers and Wégria, 1940; Leeds, Mackay, and Mooslin, I95I ; Burn, Vaughan Williams, and Walker, 1955; Lown et al., 1963; Haft et al., 1968; Yamada et al., 1968).

Ventricular extrasystole or pacemaker beats in the territory of the $T$ wave of the electrocardiogram are the clinical equivalent of the electrical stimulus applied during the vulnerable period. This phenomenon - ' $R$ on $T$ ' (Smirk and Palmer, 1960) - is often followed by various ventricular arrhythmias (Schmidt, 1952; Lown, Kosowsky, and Klein, 1968; Watanabe and Dreifus, 1968; Büchner and Effert, 1968; Csapó, Békássy, and Lónyai, 1970). Several reports deal with the import-

ance of atrial extrasystoles in the induction of

Received 8 June 1970. atrial arrhythmias as well (Killip and Gault, 1965; Hager and Schley, I966; Reynolds et al., 1967; Haft et al., 1968; Büchner and Effert, I968; Büchner, I969). This problem and the stopping of supraventricular arrhythmias by premature beats have been analysed in detail in the case of WPW syndrome (Durrer et al., 1967; Massumi, Kistin, and Tawakkol, 1967; Zeft and McGowan, 1969). In the following report we are presenting our observations on eliciting atrial arrhythmias by ventricular premature beats in clinical material and in animal experiments.

\section{Subjects and methods}

The clinical observations have been performed in our intensive care unit. Patients with arrhythmia and those after electrocardioversion have been continuously monitored on an electrocardiogram built into the central monitoring system of Hellige.

Mongrel dogs weighing ro- $14 \mathrm{~kg}$. were used in our animal experiments. A pacemaker electrode was introduced into the right atrium and hence into the right ventricle through the jugular vein 
using chloralose (0.10 g. $/ \mathrm{kg}$.) anaesthesia under continuous monitoring on an electrocardiogram. The correct position of the electrode was verified by $x$-ray. The electrodes were connected to the Medtronic type pacemaker and the heart was stimulated for 3 to 6 minutes, with a frequency of 40 to $60 / \mathrm{min}$. The intensity of the impulse was selected to equal three times the diastolic threshold impulse. Pacemaker stimulation was stopped then and acetylcholine drip ( 0.8 to $\mathrm{I} \cdot 0 \mathrm{mg}$. $/ \mathrm{min}$.) was introduced into the femoral vein of the animals. After the development of the decreased frequency ensuing after acetylcholine drip, pacemaker stimulation was started again. In a part of our experiments the right atrium was stimulated first, followed by the right ventricle; in another part the right ventricle was stimulated exclusively. The electrocardiogram was registered in each period of stimulation. If atrial arrhythmia occurred, acetylcholine infusion and pacemaker stimulation were suspended until the rhythm returned to normal.

\section{Results}

Clinical results In our clinical material, 42 episodes in 5 patients have been observed, where atrial arrhythmias have been elicited by ventricular premature beats or by parasystolic beats occurring on the descending limb of the $P$ wave or immediately after the $\mathbf{P}$ wave, in other words by ' $R$ on $P$ ' ventricular beats. These ventricular beats followed the $P$ wave of basic rhythm (P-Es distance) by 0.04$0 \cdot 10$ sec. The frequency of occurrence of such ventricular premature beats and the types of atrial arrhythmias during the period of observation are shown in Fig. $x$.

A shift of the site of atrial stimulus formation was noted in 8 cases; in 7 after ' $R$ on $P$ ' ventricular extrasystole or parasystole (Fig. 2) and in one after a normal sinus beat.

Single atrial premature beats were registered in 36 cases during the period of observation: in 9 after ' $R$ on $P$ ' ventricular beats
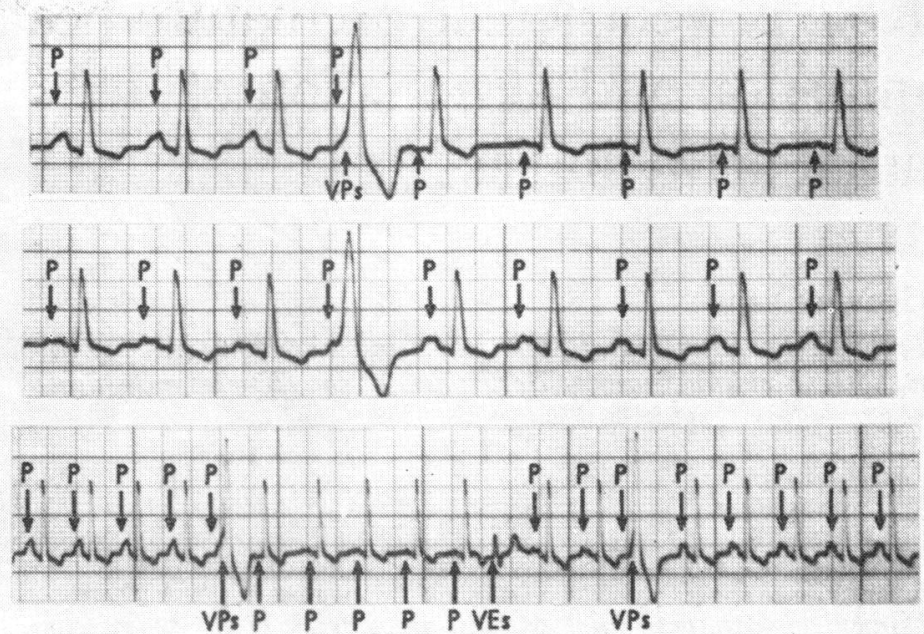

FIG. 2 Alteration of the site of atrial stimulus formation after ventricular extrasystole (VEs) with ventricular parasystole $(V P s)$.

(Fig. 3), in 26 after sinus beats, and in I after a ventricular premature beat.

Serial atrial premature beats were seen in I6 cases: in I5 after ' $R$ on $P$ ' ventricular beats (Fig. 4) and in I after a sinus beat.

Atrial fibrillation was seen in II cases, in each case after ' $R$ on $P$ ' premature ventricular beats (Fig. 5).

In 2 of our patients, in a total of 7 episodes it was seen that the atrial arrhythmia elicited by the ' $R$ on $P$ ' ventricular beat stopped immediately after a premature ventricular beat (Fig. 4 and 5). These premature ventricular beats were separated from the preceding QRS complex (Q-Es distance) always by 0.42 to $0.46 \mathrm{sec}$.

FIG. I Data of the human observations. See text for discussion.

\begin{tabular}{|c|c|c|c|c|c|c|c|c|c|c|c|}
\hline \multicolumn{3}{|c|}{$\begin{array}{l}\text { Number of heart beats during } \\
\text { period of ECG registration }\end{array}$} & \multicolumn{9}{|c|}{ Types of atrial arrhythmias } \\
\hline \multirow[t]{3}{*}{$\begin{array}{l}\text { Sinus } \\
\text { beats }\end{array}$} & \multicolumn{2}{|c|}{$\begin{array}{c}\text { Ventricular parasystoles and } \\
\text { extrosystoles }\end{array}$} & \multirow{2}{*}{\multicolumn{2}{|c|}{$\begin{array}{l}\text { Inversion } \\
\text { of P woves }\end{array}$}} & \multirow{2}{*}{\multicolumn{3}{|c|}{$\begin{array}{c}\text { Atrial } \\
\text { extrosystoles }\end{array}$}} & \multirow{2}{*}{\multicolumn{2}{|c|}{$\begin{array}{c}\text { Episodes } \\
\text { of series } \\
\text { of atrial } \\
\text { extrosystoles }\end{array}$}} & \multirow{2}{*}{\multicolumn{2}{|c|}{$\begin{array}{l}\text { Episodes } \\
\text { of atrial } \\
\text { fibrillation }\end{array}$}} \\
\hline & on & Other & & & & & & & & & \\
\hline & 61 & i) & $\begin{array}{l}\text { After } \\
R \text { on } P \\
\text { beats }\end{array}$ & $\begin{array}{l}\text { After } \\
\text { sinus } \\
\text { beats }\end{array}$ & $\begin{array}{c}\text { After } \\
R \text { on } P \\
\text { beats }\end{array}$ & $\begin{array}{l}\text { After } \\
\text { sinus } \\
\text { beats }\end{array}$ & $\begin{array}{c}\text { After } \\
\text { other } \\
\text { ventri- } \\
\text { cular } \\
\text { extra- } \\
\text { systoles }\end{array}$ & $\begin{array}{c}\text { After } \\
R \text { on } P \\
\text { beats }\end{array}$ & $\begin{array}{l}\text { After } \\
\text { sinus } \\
\text { beats }\end{array}$ & $\begin{array}{c}\text { After } \\
R \text { on } P \\
\text { beats }\end{array}$ & $\begin{array}{l}\text { After } \\
\text { sinus } \\
\text { beats }\end{array}$ \\
\hline $\begin{array}{c}8600 \\
(93 \cdot 2 \%)\end{array}$ & $\begin{array}{l}290 \\
(3.2 \%)\end{array}$ & $\begin{array}{c}330 \\
(3.6 \%)\end{array}$ & 7 & 1 & 9 & 26 & 1 & 15 & 1 & II & 0 \\
\hline
\end{tabular}


Animal results In the course of our animal experiments in Io dogs, a total of 5000 pacemaker impulses was analysed.

Fifteen hundred pacemaker impulses were recorded without acetylcholine pretreatment, consisting of 400 atrial and I 100 ventricular stimuli. Sixty-two per cent of the atrial stimulations affected the refractory period of the cycle, and 38 per cent elicited extrasystoles. Neither after the stimuli in the refractory period nor after pacemaker extrasystole were any arrhythmias observed.

Of the ventricular stimuli, 52 per cent affected the refractory period, while 48 per cent elicited ventricular premature beats. No arrhythmias have been elicited by the stimuli affecting the refractory period. In 0.8 per cent of the cases of pacemaker-induced extrasystole, repeated spontaneous premature beats were registered.

The effects of pacemaker impulses during acetylcholine infusion were twofold:

(a) Of a total of rooo atrial stimuli, 446 induced atrial extrasystoles. From the 554 impulses affecting the refractory period, 98 coincided with the descending limb of the $\mathbf{R}$ wave and with the $S$ wave or with the start of the ST segment (period of atrial vulnerability); 32 of these $(32.6 \%)$ elicited atrial fibrillation (Fig. 6), the atrial fibrillation ceasing on discontinuing acetylcholine infusion.

(b) Of 2500 ventricular 7 stimuli, 950 affected the refractory period and elicited neither premature beats nor other arrhythmias; I550 pacemaker impulses induced premature ventricular beats, and 172 stimuli applied $0.4-0$. I I sec. after the onset of the P wave induced ventricular premature beats; in 29 cases (16.9\%) this was followed by atrial fibrillation (Fig. 7), disappearing spontaneously in I case, while in the others it disappeared on discontinuing acetylcholine infusion. Apart from these occasions, pacemaker-induced premature beats were never followed by atrial arrhythmias.

\section{Discussion}

As early as 1936 Ferris et al. had already focused attention on the arrhythmia-pro- ducing effect of electrical stimuli applied in the repolarization period of the cardiac cycle. - Later, the vulnerable periods of the cardiac cycle were precisely defined, first in animal experiments, and later in patients with pacemakers and after cardioversion (Wiggers, 1940; Wiggers and Wégria, 1940; Lown et al., 1963; Haft et al., 1968); in the atria this includes the descending limbs of the $R$ and $S$ waves, and in the ventricles the ascending

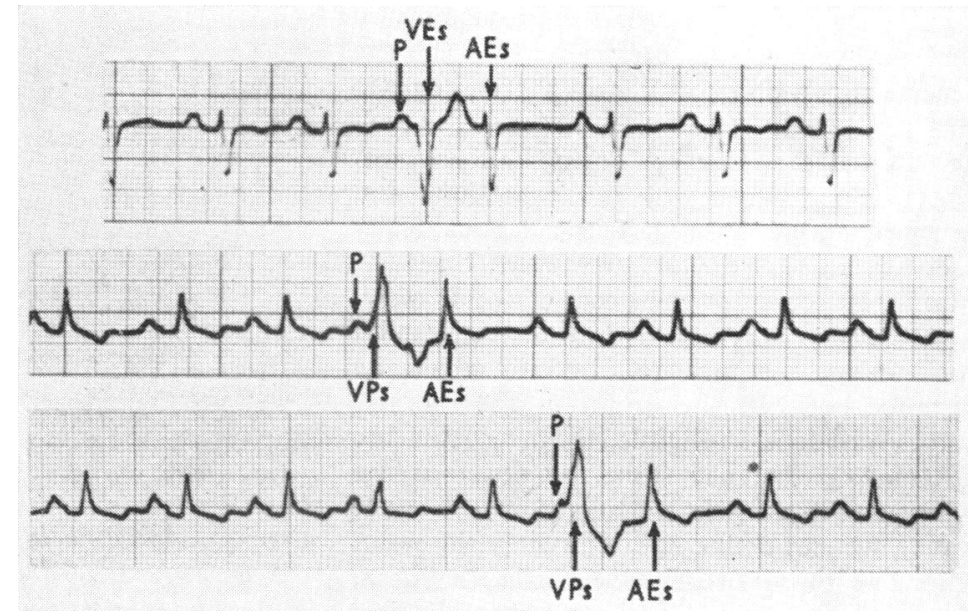

FIG. 3 Atrial extrasystole (AEs) after ' $R$ on $P^{\prime}$ ventricular extrasystole (VEs) and parasystole (VPs).

limb of the $T$ wave. Electrical impulses applied in the vulnerable periods often induce various types of arrhythmias (Wiggers and Wégria, 1940; Lown et al., 1963; Lown, Kleiger, and Wolff, 1964; Büchner, I969).

In the course of our own observations, patients with a tendency to such atrial arrhythmias have been found after ventricular extrasystoles and parasystoles occurring on the descending limb of the $P$ wave or immediately thereafter. This type of ventricular premature beat may be analysed electrophysiologically as follows (Fig. 8): as is well

FIG. 4 Serial atrial premature beats (salve) following ' $R$ on $P$ ' ventricular premature beat (VEs). Sr., sinus rhythm; $A$.Ar., atrial arrhythmia. (Reproduced by kind permission of the Editor of Orvosi Hetilap.)

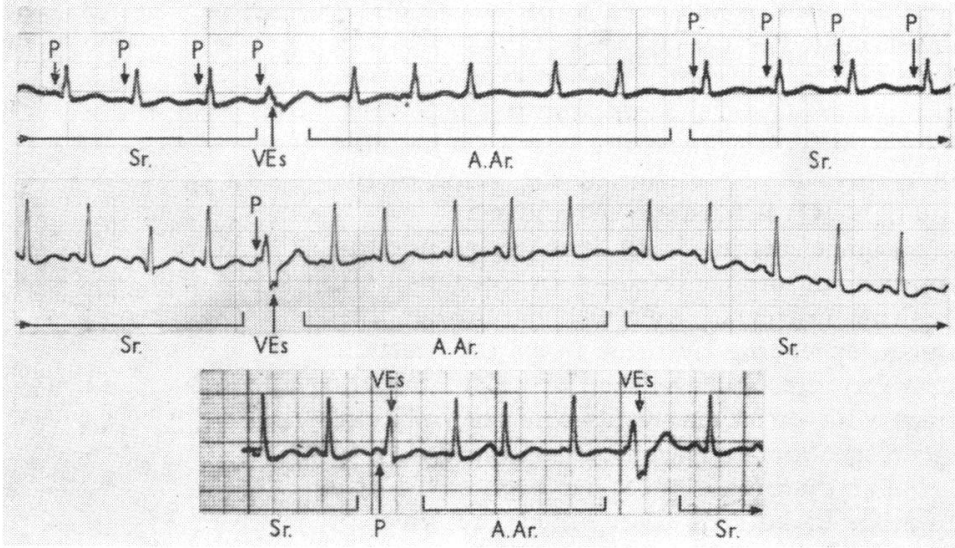


known, the impulse is conducted not only in the atrioventricular direction but in the reverse direction as well, and the orthograde and retrograde conduction times are equal, i.e. $P Q=Q P$ (Bussan, Torin, and Scherf, 1955; Linenthal et al., 1962; Siddons and Sowton, 1967). In Fig. 8 the schematically represented ventricular premature beat appears $0.05 \mathrm{sec}$. after the onset of the $P$ wave. Considering the high speed of ventricular conduction, the time required to cover the distance between the origin of the impulse and AV node is negligible. By measuring the $\mathrm{QP}$ (=PQ) distance from the onset of the premature beat (the starting point of its $R$ wave), we can define approximately the point when the impulse reached the atria. In Fig. 8, the $P Q$ interval was $0.16 \mathrm{sec}$; thus the impulse of ventricular excitation reached the atria approximately $0.2 \mathrm{I} \mathrm{sec}$. after the $P$ wave, during the $S$ wave of the electrocardiogram; in other words in the vulnerable period of the atria. The ventricular premature beat was followed by atrial arrhythmia (Fig. 4). In the course of 38 observed episodes, the premature ventricular beats preceding the atrial arrhythmias occurred after the $P$ wave (P-Es distance) by 0.04 to 0.10 sec. The $P Q$ interval varied between 0.16 and $0.18 \mathrm{sec}$. in our cases. Thus the impulse of the ventricular premature beats reached the atria approximately 0.20 to $0.28 \mathrm{sec}$. after the onset of the $P$ wave, which corresponds to the period of atrial vulnerability. For the identification of this type of ventricular premature beat the name ' $R$ on $P$ phenomenon' is suggested - on the analogue of ' $R$ on $T$ phenomenon', as introduced by Smirk and Palmer (1960). The vulnerability of these premature ventricular beats may be expressed by the following formula:

$$
\frac{\mathrm{PQ}+\mathrm{PEs}}{\mathrm{PS}}=\mathrm{Q}
$$

where $P Q$ is the length of atrioventricular conduction, PEs denotes the distance between onset of the $P$ wave and that of the premature beat, and PS is the distance between the onset of the $P$ wave and the endpoint of the $S$ wave. The ventricular premature beat is vulnerable in respect of the atrium if the value of the quotient $(Q)$ is between 0.7 and $\mathrm{I} \cdot 2$.

In our experiments in dogs we intended to reproduce our human observations. In healthy untreated animals, pacemaker impulses exceeding by three times the diastolic impulse threshold failed to produce arrhythmias with atrial and ventricular stimulation. Acetylcholine increases the susceptibility to atrial arrhythmias, and it has been noted by a number of authors that, under the effect of

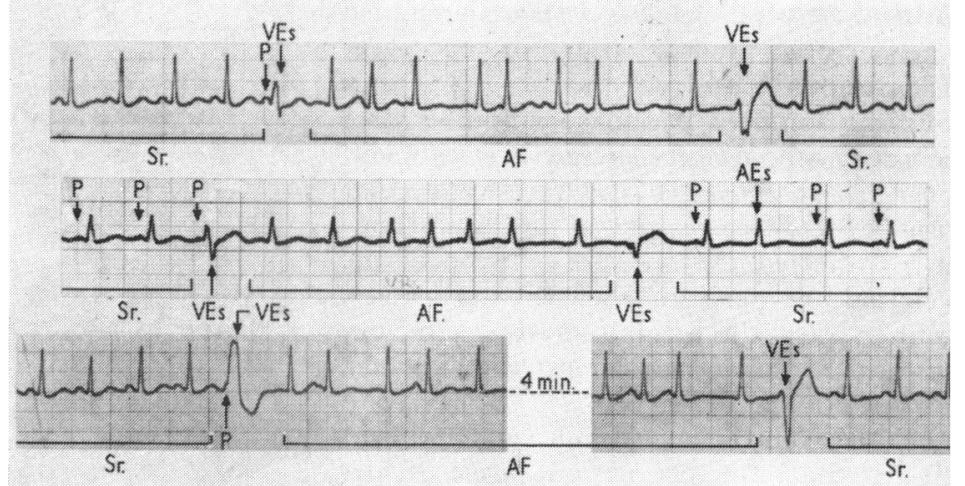

FIG. 5 Atrial fibrillation after ventricular (' $R$ on $P$ ') extrasystole and restoration of sinus rhythm after ventricular extrasystole. Sr., sinus rhythm; $A F$, atrial fibrillation; $V E s$, ventricular extrasystole; $A E s$, atrial extrasystole.

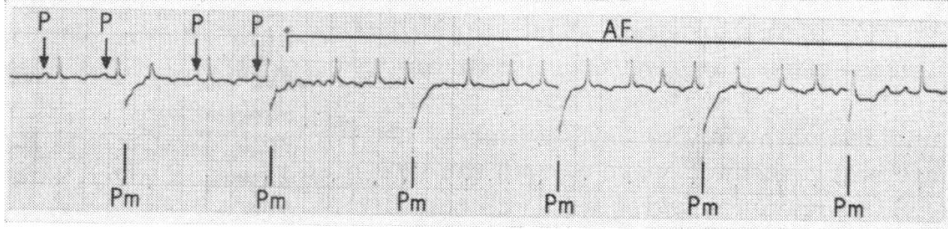

FIG. 6 Atrial pacemaker stimulation during acetylcholine infusion in animal experiment. The second stimulus which is affecting the descending limb of the $R$ wave induces atrial fibrillation. Pm, pacemaker stimulus; $A F$, atrial fibrillation.

FIG. 7 Ventricular pacemaker stimulation during acetylcholine infusion. Pacemaker premature beats occurring 0.04 to $0.11 \mathrm{sec}$. after the onset of the $P$ wave elicit atrial fibrillation. Abbreviations as in Fig. 5 and 6.
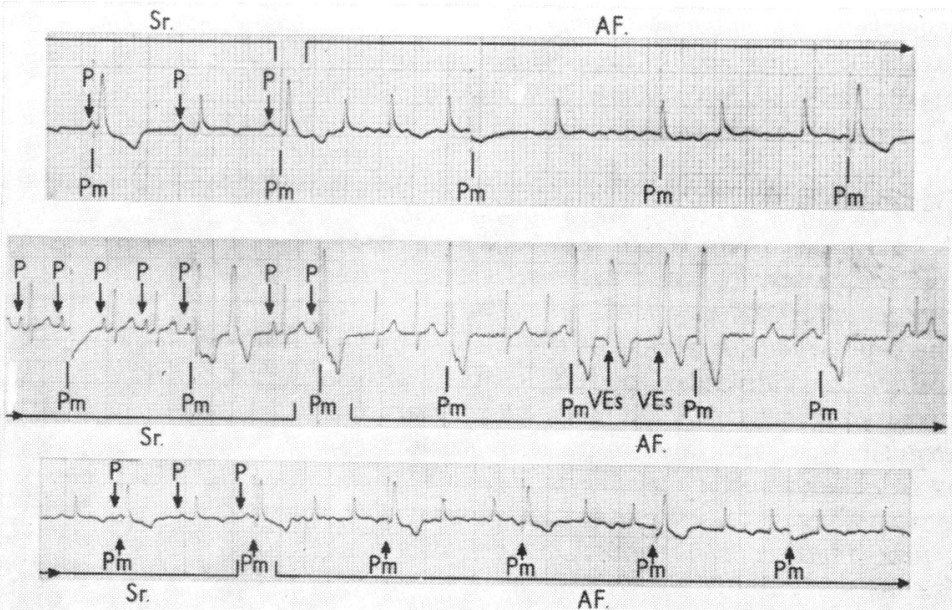
acetylcholine, pacemaker stimulation of the atrial musculature causes atrial fibrillation (Burn, 1957; Holland, Burn, and Schümann, 1957; Rand and Walker, 1958; West and Cox, r960; Yamada et al., 1968). This persists until the effect of acetylcholine stops.

By applying atrial pacemaker stimulation during acetylcholine infusion we have determined the period of atrial vulnerability, and this had been found to agree with the data already published: beats affecting the descending limb of the $R$ wave and the $S$ wave caused atrial fibrillation in $32 \cdot 6$ per cent of our cases. In the course of pacemaker stimulation of the right ventricular musculature, it has been found that pacemaker premature beats following the $\mathrm{P}$ wave by 0.04 to 0. II sec. are followed by atrial fibrillation in 16.9 per cent of the cases. The $P Q$ interval of our animals varied between 0.14 and 0.17 sec.; the impulses of these ventricular premature beats reached the atria 0.18 to $0.28 \mathrm{sec}$. after the onset of the $P$ wave; in other words in the period of atrial vulnerability. The values of the quotient (PQ+PEs)/PS were in the case of premature beats between 0.7 and I.2.

In the case of Durrer et al. (1967), supraventricular tachycardia associated with the WPW syndrome was terminated by right ventricular pacemaker extrasystole when the stimulation followed the onset of $Q$ wave by $0.40-0.46 \mathrm{sec}$. Massumi et al. (1967) terminated supraventricular tachycardias developing during heart catheterization by extrasystoles similarly timed. Zeft and McGowan (1969) reported cases of supraventricular tachycardia successfully treated by prolonged pacing of the right ventricle. In our own cases we have seen 7 episodes in 2 patients where atrial arrhythmias were interrupted by a spontaneous ventricular premature beat and this was followed by restoration of sinus rhythm (Fig. 4 and 5). These ventricular premature beats occurred in each case 0.42 to $0.46 \mathrm{sec}$. after the $\mathrm{Q}$ wave. No similar phenomena have been encountered in our animal experiments.

Summarizing our clinical observations and our animal experiments, it can be concluded - that in states susceptible to atrial arrhythmias these can be elicited either by atrial pace- maker stimulation in the period of atrial vulnerability or by spontaneous or pacemakerinduced ventricular premature beats occurring 0.04-0.II sec. after the onset of $P$ wave. These ventricular premature beats form a fusion PQRS complex with the preceding $\mathbf{P}$ wave very similar in its appearance to the WPW syndrome. It might therefore be

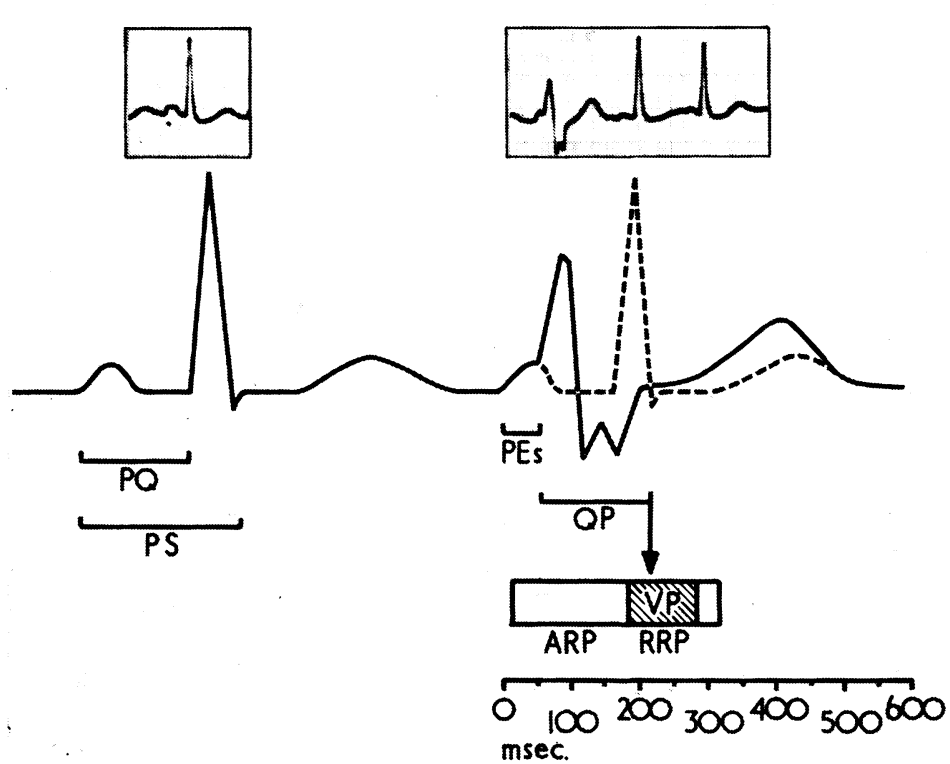

$$
\mathrm{Q}=\frac{\mathrm{PQ}+\mathrm{PES}}{\mathrm{PS}}=\frac{0.16+0.05}{0.23}=\frac{2 \mathrm{I}}{23}=0.9 \mathrm{I}
$$

FIG. 8 Schematic illustration of an ' $R$ on $P$ ' premature beat (which is visible in Fig. 3 in the second line). ARP, absolute refractory period; $R R P$, relative refractory period. See text for discussion.

assumed that a similar mechanism could play a role in triggering supraventricular tachycardias associated with WPW syndrome. Our clinical observations support the possibility that where supraventricular paroxysmal rhythmic disturbances stop spontaneously, the spontaneously occurring ventricular premature beat might also play a role. We agree with Durrer et al. (1967) that the impulse of the premature ventricular beat, by reaching the atrioventricular node or the atria, disrupts the circus movement or else defibrillates the atria.

The author is grateful to Mrs. Mária Lozsádi for preparing the electrocardiograms in our intensive care unit.

\section{References}

Büchner, M. (1969). Zur Physiologie und Pathophysiologie der Erregungsbildung im menschlichen Herzen. Archiv für Kreislaufforschung, 60, 327.

$\longrightarrow$, and Effert, S. (1968). Extrasystolie und Herzflimmern. Zeitschrift für Kreislaufforschung, 57, 18.

Burn, J. H. (1957). Acetylcholine and cardiac fibrillation. British Medical Bulletin, 13, 181.

-, Vaughan Williams, E. M., and Walker, J. M. (1955). The effects of acetylcholine in the heartlung preparation including the production of auricular fibrillation. fournal of Physiology, 128, 277. 
Bussan, R., Torin, S., and Scherf, D. (1955). Retrograde conduction of ventricular extrasystoles to the atria. American fournal of the Medical Sciences, 230, 293.

Csapó, G., Békássy, S., and Lónyai, T. (1970). Die Anwendung von beta-Rezeptorstimulantien bei Vorhof- und Kammerflimmern. Zeitschrift für Kreislaufforschung, 59, 493.

Durrer, D., Schoo, L., Schuilenburg, R. M., and Wellens, J. J. (1967). The role of premature beats in the initiation and the termination of supraventricular tachycardia in Wolff-Parkinson-White syndrome. Circulation, 36, 644 .

Ferris, L. P., King, B. G., and Spence, P. W. (1936). The effect of electrical shock on the heart. Electrical Engineering (New York), 55, 498.

Haft, J. I., Lau, S. H., Stein, E., Kosowsky, B. D., and Damato, A. N. (I968). Atrial fibrillation produced by atrial stimulation. Circulation, 37, 70 .

Hager, W., and Schley, G. (1966). Elektrokardiographische Beobachtungen nach Kardioversion. Zeitschrift für Kreislaufforschung, 55, 697.

Holland, W. C., Burn, J. H., and Schümann, H. J. (1957). Production of auricular fibrillation by electrical stimulation of isolated rabbit auricles in the presence of acetylcholine. Fournal of Pharmacology and Experimental Therapeutics, 119, 153.

Killip, T., and Gault, J. H. (1965). Mode of onset of atrial fibrillation in man. American Heart fournal, 70, 172.

Leeds, S. E., Mackay, E. S., and Mooslin, K. (1951). Production of ventricular fibrillation in dogs by means of accurately measured shocks across exposed heart. American fournal of Physiology, 165, I79.

Linenthal, A. J., Zoll, P. M., Garabedian, G. H., and Hubert, K. (1962). Retrograde conduction to the atria from electric stimulation of the ventricles in man. Circulation, 26, 752.

Lown, B., Bey, S., Perlroth, M., and Abe, T. (1963). Comparative studies of ventricular vulnerability to fibrillation. Fournal of Clinical Investigation, 42, 953.

-, Kleiger, R., and Wolff, G. (1964). The technique of cardioversion. American Heart fournal, 67, 282. -, Kosowsky, B. D., and Klein, M. D. (1968). Pathogenesis, prevention and treatment of arrhythmias in myocardial infarction. Circulation, 45, IV-26I.
Massumi, R. A., Kistin, A. D., and Tawakkol, A. A. (1967). Termination of reciprocating tachycardia by atrial stimulation. Circulation, 36, 637 .

Rand, M. J., and Walker, J. M. (1958). A comparison of antifibrillatory drugs in the heart-lung preparation. British fournal of Pharmacology and Chemotherapy, 13, 107.

Reynolds, E. W., MacDonald, W. J., Greenfield, B. M., and Semion, A. A. (1967). Mechanisms of onset and termination of abnormal cardiac rhythm studied by constant monitoring. American Heart fournal, 74, 473.

Schmidt, W. (1952). Kammer-Extrasystolen äusserster Vorzeitigkeit als Vorläufer Morgagni-AdamsStokesscher Anfälle. Zeitschrift für Kreislaufforschung, 41, 590.

Siddons, H., and Sowton, E. (1967). Cardiac Pacemakers. Charles C. Thomas, Springfield, Illinois.

Smirk, F. H., and Palmer, D. G. (1960). A myocardial syndrome. American fournal of Cardiology, 6, 620 .

Watanabe, Y., and Dreifus, L. S. (I968). Newer concepts in the genesis of cardiac arrhythmias. American Heart fournal, 76, II4.

West, T. C., and Cox, A. R. (1960). Single fiber recording during the production and control of flutter in the isolated atrium of the rabbit. Fournal of Pharmocology and Experimental Therapeutics, r30, 303.

Wiggers, C. J. (1940). The mechanism and nature of ventricular fibrillation. American Heart fournal, 20, 399.

—, and Wégria, R. (1940). Ventricular fibrillation due to single, localized induction and condenser shocks applied during the vulnerable phase of ventricular systole. American fournal of Physiology, $128,500$.

Wolf, G. A., Veith, F., and Lown, B. (1968). A vulnerable period for ventricular tachycardia following myocardial infarction. Cardiovascular Research, 2, III.

Yamada, K., Okajima, M., Hori, K., Fujimo, T., Muraki, H., Hishida, H., and Kobayaski, T. (1968). On the genesis of the absolute ventricular arrhythmia associated with atrial fibrillation. Circulation Research, 22, 707.

Zeft, H. J., and McGowan, R. L. (1969). Termination of paroxysmal junctional tachycardia by right ventricular stimulation. Circulation, 40, 919. 